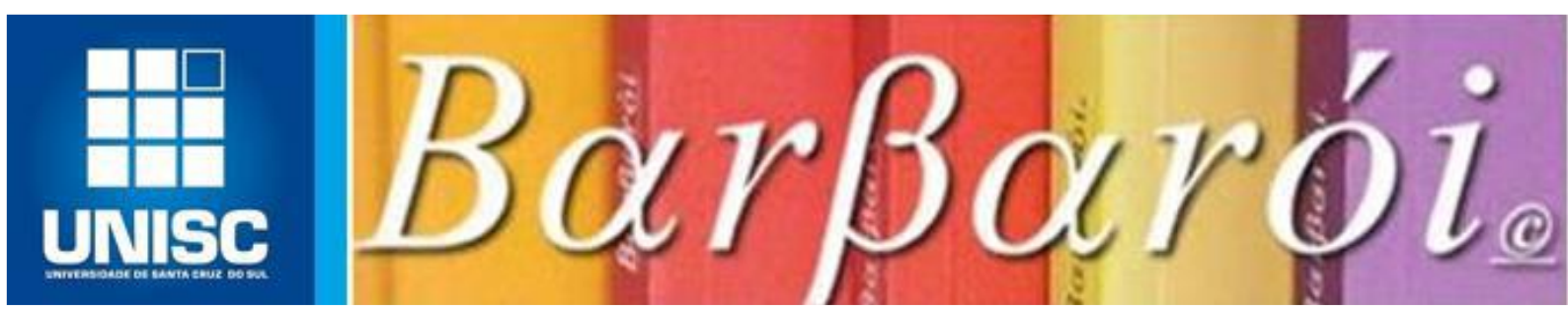

\title{
AUTOCONCEITO EM ADOLESCENTES E SUAS RELAÇÕES COM DESEMPENHO ESCOLAR E PRÁTICAS PARENTAIS
}

\author{
DOI: http://dx.doi.org/10.17058/barbaroi.v0i58.4320

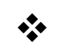

\author{
André Lesina Sacilotto \\ Universidade Franciscana - UFN - Brasil \\ Josiane Lieberknecht Wathier Abaid \\ Universidade Franciscana - UFN - Brasil

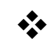

\section{Resumo}

O autoconceito pode ser concebido como uma construção teórica que o indivíduo realiza sobre si a partir de sua interação com o meio social, que assume importante papel na compreensão do processo de desenvolvimento humano. Variáveis como desempenho escolar e práticas educativas parentais tem sido relatadas como relevantes para o estabelecimento do autoconceito. Tendo em vista a relevância do tema na adolescência o presente artigo objetivou investigar as possíveis relações entre o autoconceito, desempenho escolar e práticas educativas dos pais, em adolescentes escolares. Fizeram parte desta pesquisa 57 adolescentes de ambos os sexos, com idades entre 12 e 16 anos $(M=13,44$; $D P=1,13)$ do $6^{\circ}$ ao $9^{\circ}$ ano de uma escola pública de Ensino Fundamental. Para isso, foram utilizados a Escala de Autoconceito Infanto -Juvenil (EAC-IJ), a Escala de Responsividade e Exigência Parental e análise documental na escola para o desempenho escolar. Os resultados demonstraram que houve correlação significativa entre as variáveis do estudo, destacando-se as correlações estabelecidas entre autoconceito e desempenho escolar, desempenho escolar e exigência da mãe, assim como do autoconceito com a responsividade do pai. Discute-se sobre a importância da qualidade da relação familiar e do grupo de amigos no estabelecimento do autoconceito dos adolescentes.

Palavras-chave: Autoconceito. Psicologia educacional. Práticas parentais. Adolescência.

\section{Introdução}

A educação é direito de todos e é através dela que se dá o processo de construção de conhecimento e desenvolvimento de cidadãos, para que esses possam compreender o mundo e nele estabelecer suas relações. É, fundamentalmente, na escola que ela se legitima. 
A escola constitui-se em um espaço diversificado de desenvolvimento e aprendizagem para o adolescente, isto é, um local que reúne uma gama de conhecimentos, atividades, regras e valores, também permeados por diferenças, dificuldades e problemas (MAHONEY, 2002). É nesse espaço físico, psicológico, social e cultural que os indivíduos processam o seu desenvolvimento global, mediante as atividades programadas e realizadas pela mesma (REGO, 2003). Um dos aspectos vivenciados nesse ambiente é a formação e desenvolvimento do autoconceito nos adolescentes que, de acordo com Serassuelo (2007), se dá a partir da resposta social (feedback) e da capacidade de interpretar o meio e seu sucesso pessoal. Dessa forma ele pode ser influenciado e influenciar o desempenho escolar, assim como as práticas parentais. Por exemplo, adolescentes que possuem um ambiente familiar não favorável, onde as relações estabelecidas pelos pais não são harmoniosas, afetivas e solidárias, tendem a desenvolver um baixo autoconceito familiar. Consequentemente este fato pode se refletir na vida escolar através de um baixo rendimento e de desinteresse pelos estudos, pois a qualidade da relação familiar tem impacto importante em vários aspectos da vida do adolescente (PEIXOTO, 2004).

Assim, faz-se necessário investigar as possíveis relações entre autoconceito, desempenho escolar e práticas educativas dos pais em adolescentes escolares. Uma vez que a Educação Brasileira vem sendo marcada por altos índices de repetência e evasão escolar, entende-se que pesquisar questões relacionadas ao autoconceito podem contribuir para a compreensão de tal realidade.

\section{Adolescência}

Para Ozella (2002), a adolescência não é caracterizada como uma fase inerente ao desenvolvimento do homem, mas, sim, um processo que se constrói historicamente. Ela é um momento interpretado pelo homem, onde a sociedade destaca e significa algumas marcas como, por exemplo, as mudanças corporais e o desenvolvimento cognitivo (tão evidenciados na adolescência).

Nesse período, o corpo se desenvolve e tem suas características próprias, porém nenhum componente fisiológico terá expressão direta em sua subjetividade. Os significados dados às características fisiológicas desse período são feitos pelos adultos e pela sociedade. Por exemplo, a sociedade tem atribuído aos seios da menina em desenvolvimento uma característica de sensualidade, com menos destaque para uma possibilidade de amamentar seus filhos futuramente. Da mesma forma, a força muscular dos meninos já teve um 
significado de possibilidade de trabalhar, caçar e lutar, mas hoje representa beleza e sensualidade (BOCK, 2004; OZELLA, 2002).

Assim, o jovem não é algo por natureza, pois suas características vão aparecendo em suas relações sociais, num processo em que ele se coloca por inteiro, com seu corpo e suas características como indivíduo. Ele está no social, com suas características que são interpretadas nessas relações e servem de modelo para sua construção pessoal. Sendo assim é importante ressaltar que o social não é igual ao subjetivo, existe um trabalho de construção individual e há um mundo psíquico de origem social, com uma estrutura e dinâmica próprias. O mundo psíquico constitui-se de configurações pessoais, mesclados por afetos e significações dando sentido às experiências do indivíduo. Esses elementos do mundo psíquico vêm do mundo social, mas não são idênticos a ele (FURTADO, 2001; OZELLA, 2002).

A criação histórica da adolescência vem definida por um período de latência social constituída a partir da sociedade capitalista, gerada por questões de ingresso no mercado de trabalho e extensão do período escolar, da necessidade do preparo técnico e da necessidade de justificar o distanciamento do trabalho de um determinado grupo social (OZELLA, 2002).

Esse período da vida do indivíduo é de extrema importância, pois, segundo Vigotski (2001), é nele que o indivíduo consegue realizar operações lógicas e utilizar-se do raciocínio abstrato, fazendo uso exclusivo do sistema linguístico. Além disso, é através da comunicação com os outros que a cultura é apropriada pelo indivíduo em um processo de internalização da atividade interpessoal que, gradativamente, se torna intrapessoal e regulada pela consciência, por meio da mediação da linguagem. A cultura também é de fundamental importância para a permanente transformação e consequente atribuição de novos sentidos às experiências sociais do jovem, sendo diretamente influenciado pelas práticas educativas dos pais, as quais se refletirão na forma como o jovem se vê. Desse modo, a forma como o adolescente se percebe nas relações estabelecidas com os outros no âmbito social, escolar e familiar vai influenciar diretamente no processo da construção de sua identidade que, por sua vez, se refletirá em seu autoconceito.

\section{Autoconceito}

O autoconceito tem sido definido por Sisto e Martinelli (2004 a) como o conhecimento que o indivíduo tem sobre si mesmo, abrangendo os aspectos cognitivos, afetivos e comportamentais, sendo assim um conceito multidimensional. Ele é também definido e influenciado por meio da interação que ocorre entre indivíduo e ambiente configurando-se 
constantemente nas interações sociais com os demais. Assim, a percepção que o indivíduo tem sobre si mesmo está determinada pela percepção das reações que os outros têm para com ele.

De acordo com Suehiro et al. (2009), o aspecto cognitivo do autoconceito pode ser compreendido como um conjunto de características denominadas pela própria pessoa que descreve a maneira como ela se comporta e seu jeito de ser, que não é necessariamente verdadeiro ou objetivo. $\mathrm{O}$ aspecto afetivo engloba os sentimentos e as emoções que acompanham a descrição de si mesmo. E o aspecto comportamental passa a ser influenciado diretamente pelo conceito que a pessoa tem de si mesma.

Na visão de Sisto e Martinelli (2004 a), crianças e adolescentes podem ter seu autoconceito influenciado por diversos contextos como o familiar, o escolar, o meio social, a idade, a raça, o gênero e os aspectos físicos. Pressupõe-se que, no ambiente familiar, ocorre o estabelecimento de vínculos que podem ser harmoniosos, afetivos e solidários ou cobertos de sentimentos maldosos e de ressentimentos. Quando a família constitui vínculos saudáveis, com uma educação que estabelece limites claros e disciplina firme, mas sem negar afeto, o desenvolvimento do autoconceito familiar do adolescente poderá ser positivo. Já o autoconceito escolar está relacionado com as capacidades, realizações e avaliações que o adolescente tem de si mesmo nesse contexto. Dessa forma, se a criança vivenciou momentos de fracasso em suas relações familiares, poderá levar essa experiência para a escola, o que poderia lhe causar sentimentos de insegurança e falta de confiança na adolescência. Entendese, assim, que o autoconceito pode ser um fator relevante quanto ao desenvolvimento e desempenho do adolescente no ambiente escolar, podendo contribuir positiva ou negativamente para o mesmo.

\section{Desempenho escolar}

Segundo Sisto (2002), o baixo rendimento escolar é uma das manifestações mais evidentes das dificuldades de aprendizagem. Se uma criança ou adolescente apresenta um bom desempenho escolar, mesmo que ele possua alguma dificuldade na escola e a compense com muito esforço superando-a, esse jovem poderia passar despercebido. Da mesma forma, aqueles que não estudam por falta de interesse ou de motivação correm o risco de serem classificados como portadores de dificuldades de aprendizagem. Assim, as generalizações excessivas podem, por vezes, levar a confusões conceituais sérias em que pouco ou quase nada ajudam no diagnóstico das possíveis causas dos problemas de aprendizagem. 
O desempenho escolar da criança e do adolescente deveria ser avaliado levando-se em conta não apenas suas características pessoais, mas também seu ambiente familiar e escolar, pois tais fatores interagem entre si podendo ora facilitar, ora prejudicar o aluno, suas potencialidades e habilidades (SANTOS; GRAMINHA, 2005). No âmbito da aprendizagem, a interação de aspectos pessoais e contextuais pode contribuir tanto para o sucesso como para o fracasso educacional. Tal compreensão é compatível com a concepção sistêmica, na qual o baixo rendimento escolar deve ser atribuído não só às características individuais, mas também ao seu contexto familiar, escolar e social (PAMPLIM, 2005).

Sisto (2002) reforça esta ideia quando enfatiza a existência de uma interação entre fatores sociais, educativos e individuais como possíveis explicações para as questões da aprendizagem. Dessa forma, o fracasso escolar tem sido um dos temas mais discutidos e explorados pela literatura científica, sendo possível constatar que, apesar de não se tratar de uma questão nova, trata-se de uma questão em aberto, uma vez que inúmeras variáveis podem contribuir com o bom andamento do processo de aprendizagem, sejam fatores ditos afetivoemocionais, ambientais, orgânicos e culturais (ROSSINI; SANTOS, 2002). Entre esses fatores, pode estar a percepção sobre as práticas educativas dos pais.

\section{Percepção sobre práticas educativas dos pais}

Segundo Banaco e Martone (2001), a família é o grupo que primeiramente aplica os procedimentos de reforço e punição sobre os comportamentos dos indivíduos, de acordo com os critérios culturais. Então, é ela que inicialmente prepara o indivíduo para as suas primeiras relações com o mundo e demais grupos sociais, influenciando, assim, a maneira como as pessoas irão se comportar e reagir, ou seja, seu modo de ser no cotidiano.

Por isso, Hoffman (1975) definiu as práticas parentais em duas categorias: as indutivas, que sinalizam à criança e ao adolescente as consequências de seus atos, levando-as à reflexão; e as coercitivas, que incluem atitudes disciplinares que envolvem força, punição física e privações. Para Maccoby e Martin (1983) tais práticas são formadas por duas dimensões, a exigência e a responsividade. A primeira se refere ao quanto os pais conseguem controlar e supervisionar o comportamento de seus filhos, estabelecendo regras claras e limites; e a segunda, à comunicação, suporte emocional e afetividade dos pais em relação a eles. Com base nessas duas dimensões, os autores definiram quatro estilos parentais: democrático, com alta exigência e responsividade; autoritário, alta exigência e baixa responsividade; permissivo, baixa exigência e alta responsividade e negligente, baixa 
exigência e responsividade. Com isso, é possível entender que os comportamentos dos pais influenciam diretamente o desenvolvimento das crianças e dos adolescentes, bem como fornecem modelos para a constituição do repertório comportamental dos filhos.

Logo, o estilo parental é o resultado da confluência de forças das práticas educativas parentais que vão influenciar no autoconceito dos adolescentes, uma vez que o mesmo é aprendido ao longo da vida, e são os pais os determinantes iniciais para o desenvolvimento do mesmo. Na mesma medida, os estilos parentais podem influenciar o desempenho escolar como, por exemplo, quando famílias mais rígidas e autoritárias tendem a formar filhos que se esforcem mais na escola, mas são pouco afetivos e criativos.

Ao observar a importância de tais questões, objetivou-se investigar as possíveis relações entre o autoconceito, desempenho escolar e práticas educativas dos pais, em adolescentes escolares, bem como se existem diferenças por sexo e faixa etária quanto às variáveis do estudo.

\section{Método}

A presente pesquisa teve delineamento transversal com abordagem quantitativa. De acordo com Cozby (2003), a abordagem quantitativa enfatiza os dados estatísticos e utiliza os números obtidos como forma de compreender os fenômenos e variáveis estudadas.

\section{Participantes}

Participaram neste estudo 57 adolescentes de ambos os sexos (média de idade 13,44 anos; $\mathrm{DP}=1,13)$ que frequentavam o Ensino Fundamental, divididos em $6^{\circ}, 7^{\circ}, 8^{\circ}$ e $9^{\circ}$ anos, de uma escola da rede de ensino público de uma cidade do interior do Rio Grande do Sul. Os critérios para inclusão na pesquisa foram: aceitar participar do estudo, ter consentimento dos pais e ser capaz de compreender e responder aos instrumentos. O último dado foi coletado junto à escola previamente. O tamanho da amostra foi calculado considerando-se a recomendação de Dancey e Reidy (2006) para execução de análises com a finalidade de verificar associação entre variáveis. A amostra foi composta por conveniência, uma vez que participaram do estudo apenas os alunos que tiveram autorização dos responsáveis e estavam presentes no dia da aplicação.

\section{Instrumentos}

Para a realização da pesquisa foram utilizados os seguintes instrumentos: 
-Escala de Autoconceito Infanto -Juvenil (EAC-IJ)

Trata-se de um instrumento capaz de avaliar os diferentes níveis de autoconceito de crianças e adolescentes pertencentes à faixa etária de 8 a 16 anos, nos âmbitos social, escolar, familiar e pessoal. A EAC-IJ teve sua validade comprovada por meio da análise fatorial, tendo sido composta, ao final, por um questionário de 20 itens distribuídos entre quatro âmbitos (familiar, social, escolar e pessoal), obtendo 41,09\% de variância explicada. Os coeficientes de consistência interna de Cronbach variaram entre 0,59 e 0,62, e para o escore total, a precisão foi de 0,78 . Para cada item da escala, o sujeito tem três alternativas: responder como ele se comporta, o que sente ou o que pensa. As opções de respostas variam em "sempre", “às vezes" ou "nunca" (SISTO; MARTINELLI, 2004 b).

- Escala de Responsividade e Exigência Parental

Trata-se de um instrumento composto por 24 itens, sendo12 relacionados à percepção de responsividade e a outra metade referente à exigência parental na visão dos adolescentes. $\mathrm{O}$ participante deve marcar o quanto a afirmação descreve as atitudes de seus pais e mães. Para isso, existe uma chave de respostas em formato de escala Likert de cinco pontos. O instrumento demonstrou, em seu estudo original, uma elevada consistência interna para Escala de Exigência combinada- pai e mãe (Alfa de Cronbach=0,81) e para a Escala de Responsividade combinada (Alfa de Cronbach=0,91) (TEIXEIRA, BARDAGI \& GOMES, 2004).

- Análise documental sobre desempenho escolar. A mesma foi feita através da consulta às notas dos participantes, fornecida pela escola, onde foi realizada uma média total do desempenho do aluno, podendo variar de 0 a 10 em que a média considerada para aprovação era 6

- Ficha de dados sociodemográficos: A ficha contém dados sobre a composição familiar dos adolescentes, sexo, idade, profissão (dos pais) e escolaridade de todos os envolvidos.

\section{Considerações éticas}

A presente pesquisa foi avaliada e aprovada pelo plenário do Comitê de Ética em Pesquisa com Seres Humanos do Centro Universitário Franciscano (CAEE n.19459913.8.0000.5306) por estar de acordo com as normas vigentes na Resolução $\mathrm{n}^{\circ}$. 466/2012 do Conselho Nacional de Saúde/Ministério da Saúde (2013). Os responsáveis pelos participantes assinaram o Termo de Consentimento Livre e Esclarecido que apresentava informações básicas sobre o projeto, bem como enfatizava o respeito aos aspectos éticos 
referentes à pesquisa, incluindo o direito das participantes interromperem a sua participação no estudo a qualquer momento, se assim desejassem, bem como o resguardo a sua identidade.

\section{Procedimento de análise de dados}

A coleta de dados foi realizada na escola, durante o horário de aula, depois de obtidas as autorizações do Comitê de Ética em Pesquisa de uma instituição de ensino superior, da direção da escola e dos responsáveis pelo aluno (Termo de Consentimento Livre e Esclarecido). Os professores e alunos foram informados dos objetivos da investigação, sendo assegurada que sua participação foi voluntária, bem como foi garantida a confidencialidade das respostas. A aplicação foi coletiva, dividida em quatro grupos, $6^{\circ}, 7^{\circ}, 8^{\circ}$ e $9^{\circ}$ anos, e ocorreu em apenas um encontro. O primeiro instrumento respondido foi a Ficha de dados sociodemográficos, logo em seguida, os adolescentes responderam a Escala de Responsividade e Exigência Parental e por fim a Escala de Autoconceito Infanto -Juvenil (EAC-IJ). O tempo médio de aplicação dos três instrumentos foi de 40 minutos, e a coleta do desempenho escolar dos participantes foi feito em outro momento junto à supervisão da escola.

\section{Resultados e discussão}

Inicialmente, serão descritos os dados sociodemográficos dos participantes em função das seguintes variáveis: sexo, ano de escolaridade, idade, configuração familiar, participação dos pais na família, profissão dos pais e desempenho escolar. Em seguida, expõem-se as análises descritivas e relações entre o autoconceito, desempenho escolar e práticas educativas dos pais em adolescentes escolares, bem como se existem diferenças por sexo e faixa etária quanto às variáveis do estudo.

\section{Perfil dos participantes}

Em relação à variável sexo, $38(66,7 \%)$ eram do sexo feminino, e $19(33,3 \%)$ do masculino. No que se refere ao ano de escolaridade, constatou-se que 17 (29,8\%) alunos frequentavam o sexto ano, $16(28,1 \%)$ o sétimo, $8(14 \%)$ o oitavo e $16(28,1 \%)$ o nono ano de escolaridade. A idade dos estudantes da amostra variou de 12 a 16 anos $(\mathrm{M}=13,44$; $\mathrm{DP}=$ $1,13)$

As configurações familiares que mais apareceram foram a nuclear simples, em que residem na mesma casa o pai, a mãe e os filhos, com 18 (31,6\%) dos participantes, e, em 
seguida, a monoparental feminina extensa, em que residem na mesma casa a mãe, os filhos e outros adultos, com $14(24,6 \%)$ dos participantes. Referente à participação dos pais nas famílias, observou-se que, apenas para um deles $(1,8 \%)$, a mãe não foi considerada como membro familiar. Em relação ao pai, 48 (84,2\%) consideram que o mesmo faz parte da família. Em relação à variável profissão dos pais, verificou-se que grande parte das mães não trabalha formalmente, pois $16(28,1 \%)$ foram apontadas como do lar, seguido por $8(14 \%)$ como trabalhadoras do comércio local, 8 (14\%) como empregadas domésticas e 8 (14\%) como autônomas. Em relação ao pai, as profissões mais citadas foram de autônomo $(f=11$; $19,3 \%)$ e de serviços gerais $(f=10 ; 15,5 \%)$.

\section{Autoconceito e desempenho escolar}

De acordo com Paiva e Lourenço (2011), o autoconceito deve ser considerado como fator atribuído ao sucesso escolar, pois ao fazer parte do processo de aprendizagem, atua na motivação dos alunos, influenciando, por isso, no desempenho dos mesmos.

$\mathrm{Na}$ Tabela 1 são apresentados os valores encontrados referentes à média para o autoconceito e o desempenho escolar em relação ao ano escolar e no geral.

Tabela 1

Médias e Desvios-Padrão de Autoconceito e Desempenho Escolar por Ano e Geral

\begin{tabular}{lrrrrr}
\hline \multicolumn{7}{c}{ M (DP) } & & \\
\hline \multicolumn{1}{c}{ Variável } & $\mathbf{6}^{\mathbf{0}}$ & $\mathbf{7}^{\mathbf{0}}$ & $\mathbf{8}^{\mathbf{0}}$ & $\mathbf{9}^{\mathbf{0}}$ & Geral \\
\hline Autoconceito pessoal & 4,76 & 4,31 & 4,50 & 3,44 & 4,23 \\
& $(1,67)$ & $(1,13)$ & $(1,30)$ & $(1,15)$ & $(1,41)$ \\
Autoconceito escolar & $4,88^{*}$ & 2,69 & 3,13 & 3,50 & 3,63 \\
& $(1,96)$ & $(2,08)$ & $(1,55)$ & $(1,75)$ & $(2,04)$ \\
Autoconceito familiar & 5,71 & 5,13 & 4,63 & 5,25 & 5,26 \\
Autoconceito social & $(1,04)$ & $(1,14)$ & $(1,68)$ & $(1,98)$ & $(1,48)$ \\
& 8,82 & 8,19 & 8,75 & 8,88 & 8,65 \\
Autoconceito total & $(2,55)$ & $(2,56)$ & $(1,48)$ & $(2,63)$ & $(2,41)$ \\
Desempenho escolar & 24,12 & 20,31 & 21,00 & 21,06 & 21,75 \\
& $(4,89)$ & $(3,87)$ & $(4,17)$ & $(5,36)$ & $(4,82)$ \\
& 6,47 & 6,62 & 7,46 & 7,00 & 6,82 \\
& $(1,70)$ & $(1,59)$ & $(0,55)$ & $(1,07)$ & $(1,41)$ \\
\hline
\end{tabular}

Fonte: Dados da pesquisa $* p<0,02$

As médias de todas as subescalas de autoconceito no padrão geral (não dividido em ano escolar) são semelhantes às descritas por Sisto; Martinelli (2004b) e Martins; Nunes; Noronha (2008). Na presente pesquisa, as subescalas autoconceito familiar e autoconceito 
social (escore geral) obtiveram pontuação máxima (8 e 12, respectivamente), o que também foi encontrado no estudo de Martins; Nunes; Noronha (2008). É possível entender que os ambientes mais favoráveis ao desenvolvimento de um autoconceito positivo nos adolescentes da pesquisa são a família e o grupo de amigos, percebendo-se aceitos socialmente. Peixoto (2004) e Loss; Cassemiro (2010) afirmam que o suporte emocional e social fornecido pela família está associado de forma positiva com a percepção de competência e nas relações com os pares.

As médias de todos os anos no desempenho escolar, referentes ao primeiro trimestre letivo, foram satisfatórias, uma vez que a escola considera o valor 6,0 como média para aprovação. Foi possível verificar que houve uma melhora crescente em relação ao ano e desempenho escolar. Logo, o autoconceito quando relacionado com o desempenho escolar poderá ser considerado como variável motivacional para potencializar a adaptação aos diferentes níveis de ensino (PAIVA; LOURENÇO, 2011).

\section{Estilos parentais}

A média de responsividade percebida sobre as mães foi de $36,45(\mathrm{DP}=9,80)$ e a de responsividade do pai foi de $26,87(\mathrm{DP}=16,62)$; quanto à média de exigência percebida sobre as mães foi de 36,92 ( $\mathrm{DP}=8,71)$ e a de exigência dos pais 27, $76(\mathrm{DP}=16,00)$. Com base nos dados, pode-se inferir que os adolescentes consideram as mães mais responsivas e exigentes do que seus pais. Assim, conforme Teixeira, Oliveira e Wottrich (2006) entende-se que as mães oferecem maior apoio emocional, aproximação afetiva e incentivo ao desempenho, ao mesmo tempo, que supervisionam e controlam o comportamento de seus filhos se comparados a seus pais.

Quanto aos estilos parentais, utilizaram-se as quatro categorias descritas por Maccoby e Martin (1983), a saber: democrático: alta exigência e responsividade; autoritário: alta exigência e baixa responsividade; permissivo: baixa exigência e elevada responsividade; negligente: baixa exigência e responsividade.

$\mathrm{Na}$ Tabela 2 são apresentados os valores encontrados referentes à média dos estilos parentais percebidos por sexo e no geral. 
Tabela 2

Frequências e Percentuais dos Estilos Parentais Percebidos por Sexo

\begin{tabular}{lccc}
\hline \multicolumn{1}{c}{ Estilo } & \multicolumn{1}{c}{$\boldsymbol{f}(\%)$} & Total \\
\hline & Masculino & Feminino $(\mathrm{n}=31)$ & 47 \\
& & & \\
\hline Mãe Democrática & $3(15,8)$ & $9(23,7)$ & 12 \\
Mãe Autoritária & $4(21,1)$ & $7(18,4)$ & 11 \\
Mãe Permissiva & $2(10,5)$ & $5(13,2)$ & 7 \\
Mãe Negligente & $7(36,8)$ & $10(26,3)$ & 17 \\
\hline Pai Democrático & $6(31,6)$ & $11(29,7)$ & 17 \\
Pai Autoritário & $2(10,5)$ & $6(15,8)$ & 8 \\
Pai Permissivo & $4(21,1)$ & $2(5,4)$ & 6 \\
Pai Negligente & $4(21,1)$ & $14(36,8)$ & 18 \\
\hline
\end{tabular}

Fonte: Dados da pesquisa

Notas: Os percentuais referem-se a cada categoria de estilo.

No escore total, o estilo parental que mais predominou tanto para a mãe como para o pai foi o negligente. De acordo com Batista e Weber (2012), esse perfil se configura por pais que não estabelecem regras e limites, não monitoram o comportamento de seus filhos e também não se envolvem e não são afetivos com os mesmos. Em segundo lugar estão os pais (pai e mãe) de estilo democrático que, conforme Batista e Weber (2012), são pais que conseguem impor limites e regras, controlar comportamento ao mesmo tempo em que dão suporte afetivo. É importante afirmar, contudo, que o teste quiquadrado mostrou que não houve associação significativa entre o estilo dos pais e sexo.

\section{Análises inferenciais}

Constatou-se também que houve correlação significativa do total de escore de autoconceito com o desempenho escolar $(\mathrm{r}=0,30 ; p=0,017 ; \mathrm{n}=63)$, sendo que este último também se correlacionou com a subescala de autoconceito social $(\mathrm{r}=0,39 ; p=0,002 ; \mathrm{n}=63)$. Conforme Paiva e Lourenço (2011) e também Peixoto e Almeida (2011), o autoconceito tem impacto no desempenho escolar, influenciando positivamente nas notas escolares, fato esse confirmado também na presente pesquisa.

O desempenho escolar se correlacionou com a exigência da mãe $(\mathrm{r}=0,38 ; p<0,05)$, de forma que quanto maior a exigência da mesma, maior o desempenho do filho. Também foi 
possível verificar que houve correlação entre o autoconceito total com a responsividade do pai $(\mathrm{r}=0,42 ; p<0,02)$. Assim, um pai carinhoso parece proporcionar um autoconceito mais elevado em seu filho nesta amostra. Esses resultados, conforme afirmam Loss e Cassemiro (2010), constituem fatores de proteção para o adolescente, uma vez que contribuem para o desenvolvimento de sentimentos positivos, tanto em relação à família quanto a si mesmos. Foi possível constatar, a partir de um Teste Quiquadrado, que não houve diferença por sexo entre os estilos parentais da mãe ou do pai.

Realizou-se um Teste $\mathrm{t}$ para verificar diferenças entre as médias por tipo de configuração familiar (nuclear ou monoparental) e encontrou-se que os participantes percebem que os pais (sexo masculino) têm maior exigência nas famílias de configuração nuclear $(M=34,63 ; D P=9,6)$ do que nas monoparentais $(M=20,92 ; D P=18,83)$. Também foi constatado que os pais (sexo masculino) das famílias nucleares são mais responsivos ( $\mathrm{M}=$ 31,53; $\mathrm{DP}=12,89)$ do que nas monoparentais $(\mathrm{M}=22,04 ; \mathrm{DP}=19,35)$. Dessa forma é possível inferir que o fato se deu em função da maioria das famílias monoparentais serem femininas, estando o pai ausente.

Uma análise de variância (ANOVA) mostrou que não houve diferença no autoconceito entre os tipos de configuração familiar, nem por sexo. Entre os anos escolares houve diferença significativa $(\mathrm{F}(3,53)=4,014 ; \mathrm{p}=0,012)$ na subescala de autoconceito escolar. Uma análise de Pos hoc (Sheffé) mostrou que a diferença ocorreu entre sexto e sétimos anos $(p=0,017)$.

Ao realizar o Teste $\mathrm{t}(t=2,04 ; \mathrm{gl}=55 ; p<0,05)$ para verificar diferenças entre as médias de autoconceito por sexo e faixa etária, não houve diferença por sexo, porém constatou-se que, na subescala autoconceito pessoal, o grupo com idade até 13 anos possui autoconceito pessoal $(\mathrm{M}=4,55 ; \mathrm{DP}=1,32)$ maior que o grupo com maiores de 13 anos $(\mathrm{M}=3,79 ; \mathrm{DP}=1,44)$. Esse dado também foi encontrado no estudo de Sisto e Martinelli (2004b), onde a média do autoconceito pessoal sofre um declínio a partir dos 13 anos no sexo feminino, de forma que a amostra deste estudo predominantemente feminina justificaria tal resultado. Porém o referido autor afirma que não há consenso entre os autores a respeito da influência da idade no autoconceito, enquanto alguns afirmam que o fator idade influi na percepção da criança a respeito de suas habilidades e desenvolvimento cognitivo, através de seu progresso nos níveis de ensino; outros como Peixoto (2004), Loss e Cassemiro (2010) atribuem o resultado do autoconceito a uma avaliação externa de seu desempenho, através do feedback e não em função da variação de idade. 
O que mudaria com a idade e consequente chegada na adolescência seria a qualidade na relação com os pais (BRACKEN; CRAIN, 1994; PEIXOTO 2004), quando o adolescente se distancia um pouco dos pais e se aproxima mais dos pares, podendo haver uma redução no autoconceito familiar e um aumento no social. Contudo, essa inferência não pode ser investigada neste estudo por ser do tipo transversal. Para verificar o autoconceito ao longo do tempo, sugere-se, para estudos futuros, que sejam investigadas as mesmas variáveis aqui estudadas, entretanto de forma longitudinal.

\section{Conclusão}

O presente estudo buscou investigar a influência do desempenho escolar e da percepção sobre práticas educativas no autoconceito dos adolescentes, de forma que foi possível identificar correlações significativas entre as variáveis do estudo. Com base nos dados pode-se concluir que os adolescentes de forma geral apresentam um autoconceito positivo, o qual pode constituir-se como um importante mecanismo protetor contra adversidades e que os ambientes que mais influenciam os mesmos são a família e o grupo de amigos, implicando também na maneira como os mesmos se percebem.

Assim, a família, independentemente de sua configuração, exerce um papel importantíssimo no desenvolvimento dos adolescentes e de seu autoconceito. Uma vez que quanto maior a exigência, maior o desempenho escolar dos participantes, pode-se enfatizar a necessidade do acompanhamento dos pais na vida escolar de seus filhos. Da mesma forma que o conteúdo afetivo dos pais também interfere no autoconceito do adolescente (maneira como o jovem se percebe), pais exigentes e carinhosos criam ambientes favoráveis ao sucesso escolar e ao desenvolvimento de um autoconceito positivo.

Cabe ressaltar, a importância do relacionamento dos adolescentes com os pares, uma vez que quanto maior seu autoconceito social, maior seu desempenho escolar. Portanto é fundamental desenvolver vínculos e manter um grupo de amizades, principalmente nessa etapa do desenvolvimento humano, cabendo também aos pais estimular estes tipos de relacionamentos desde a infância.

Algumas limitações do estudo devem ser expostas a fim de que se possa estabelecer a extensão atingida pelo mesmo. Inicialmente é preciso indicar que o tamanho da amostra não é o ideal, pois uma amostra maior poderia indicar resultados estatísticos mais significativos e, consequentemente, mais generalizáveis a outras populações. $O$ fato de a pesquisa ter sido realizada em apenas uma escola é outro fator, porque impossibilita a comparação com outras 
realidades. Outra limitação a ser considerada refere-se ao método do estudo, que foi o transversal, que impossibilita o estabelecimento de relações causais por não provarem a existência de uma sequência temporal. Sugere-se, por fim, que novas investigações sobre a temática sejam realizadas com amostras mais representativas, uma vez que no Brasil não existem muitos estudos sobre o tema.

O estudo mostra a importância de alguns fatores que influenciam no desenvolvimento do adolescente. Destacam-se as relações familiares, o ambiente escolar e seu relacionamento social. Assim, tal resultado possibilita pensar a cerca de possíveis intervenções junto à escola, como, por exemplo oficinas aos professores. De acordo com Rocha, Ingberman e Breus (2011), esses recursos são considerados agentes motivadores capazes de contribuir para que o aluno seja mais persistente, se dedique mais aos estudos, acredite em suas capacidades e habilidades, utilize melhores estratégias de aprendizagem e lide melhor com as dificuldades presentes no ambiente escolar, que refletirão em sentimentos positivos em relação a si próprios e no desempenho escolar.

Outra possível intervenção seriam oficinas junto aos pais, a fim de orientá-los sobre a educação dos filhos, porque se percebe que eles carecem dessas informações. Para que os mesmos pudessem utilizar uma combinação adequada de exigência e responsividade, que também refletiriam tanto no autoconceito, quanto em seu rendimento escolar.

\title{
SELF-CONCEPT IN TEENAGERS AND ITS RELATIONS WITH SCHOOL PERFORMANCE AND PARENTAL PRACTICES
}

\begin{abstract}
Self-concept may be conceived as a theoretical construction that the individual has about himself from his interaction with society that assumes an important role in the comprehension of the human development process. Variables such as school performance and parental educational practices have been reported as relevant for the establishment of self-concept. Since this theme can be relevant in adolescence the present article sought to investigate the possible relations between self-concept, school performance and educational practices from parents in school-aged teens. Were part of this research 57 teenagers, from both sexes, with ages between 12 and 16 years old $(M=13,44 ; D P=1,13)$ from $6^{\text {th }}$ to $9^{\text {th }}$ years of an public elementary school. For that we used the "Escala de Autoconceito Infanto-Juvenil (EAC-IJ)", the "Escala de Responsividade e Exigencia Parental" and analysis of school papers for the school performance. The results showed that there's a significant relation between the variables of study, featuring the relations established between self-concept and school performance, school performance and mother exigency, as for self-concept and father responsiveness. We argue about the importance of a quality family relationship and group of friends in the establishment of self-concept of teenagers.
\end{abstract}

Keywords: Self-concept. Educational psychology. Parental practices. Adolescence. 


\section{AUTOCONCEPTO EN ADOLESCENTES Y SUS RELACIONES CON DESEMPEÑO ESCOLAR Y PRÁCTICAS PARENTALES}

\section{Resumen}

El autoconcepto puede ser determinado como una construcción teórica que el individuo realiza sobre sí por medio de su interacción con el medio social, que adquiere importante papel en la comprensión del proceso de desarrollo humano. Variables como el desempeño escolar y las prácticas educativas parentales han sido relatadas como relevantes para la determinación del autoconcepto. Teniendo en cuenta la relevancia del tema en la adolescencia el presente artículo tuvo como objetivo investigar las posibles relaciones entre el autoconcepto, desempeño escolar y prácticas educativas de los padres, en adolescentes escolares. Participaron de esta investigación 57 adolescentes de ambos sexos, con edades comprendidas entre 12 y 16 años $(M=13,44, S D=1,13)$ del 6 al 9 de grado de una escuela pública de enseñanza primaria. Para eso, fueron utilizadas la Escala de Autoconcepto Infantil Juvenil (EAC-IJ), la Escala de Responsividad y Exigencia Parental y análisis documental en escuela para el desempeño escolar. Los resultados demostraron que hubo correlación significativa entre las variables del estudio, resaltándose las correlaciones establecidas entre autoconcepto y desempeño escolar, desempeño escolar y exigencia de la madre, asi como del autoconcepto con la responsividad del padre. Se discute sobre la importancia de la calidad de la relación familiar y del grupo de amigos en la determinación del autoconcepto de los adolescentes.

Palabras clave: Autoconcepto. Psicología educacional. Prácticas parentales. Adolescencia.

\section{REFERÊNCIAS}

BANACO, R; MARTONE, R. Terapia Comportamental de família: uma experiência de ensino e aprendizagem. In: GUILHARDI, H. J. et al. Sobre Comportamento e Cognição: expondo a variabilidade. Santo André: Esetec, 2001.

BATISTA, A. P; WEBER, L. N. D. Estilos de liderança de professores: aplicando o modelo de estilos parentais. Psicologia Escolar e Educacional, Maringá, v. 16, n. 2, p. 299-307, 2012.

BOCK, A. M. B. A perspectiva sócio-histórica de Leontiev e a crítica à naturalização da formação do ser humano: a adolescência em questão. Cadernos CEDES, Campinas, v.24, n.62, abr. 2004. Disponível em: < http://www.scielo.br/scielo.php?pid=s010132622004000100003\&script=sci_arttext > Acesso em: 3 jun. 2013.

BRACKEN, B. A; CRAIN, R. M. Children's and adolescents' interpersonal relations: do age, race, and gender define normality? Journal of Psychoeducational Assessment, v.12, p. 14-32, 1994.

CONSELHO NACIONAL DE SAÚDE. Resolução para pesquisas envolvendo seres humanos. Resolução 466/2012. Brasília: Diário Oficial da União, 2013.

COZBY, P. C. Métodos de pesquisa em ciências do comportamento. São Paulo: Atlas, 2003.

DANCEY, C. P.; REIDY, J. Estatística sem matemática para psicologia (Lori Viali, Trad). Porto Alegre: Artmed, 2006. 
FURTADO, O. O psiquismo e a subjetividade social. In: BOCK, A. B; FURTADO, O; GONÇALVES, M. G. Psicologia sócio-histórica: uma perspectiva crítica em psicologia. São Paulo: Cortez, 2001.

HOFFMAN, M. L. Moral internalization, parental power, and the nature of parent-child interaction. Developmental Psychology, v. 11, p. 228-239, 1975.

LOOS, H.; CASSEMIRO, L. F. K. Percepções sobre a qualidade da interação familiar e crenças autorreferenciadas em crianças. Estudos de Psicologia, Campinas, v. 27, n. 3, p 293$303,2010$.

MACOBY, E; MARTIN, J. Socialization in the context of the family: parent-child interaction. In: HTHERINGTON, E. M; MUSSEM, P. H. Handbook of child psychology: Socialization, Personality and Social Development. New York: Wiley, 1983.

MAHONEY, A. A. Contribuições de H. Wallon para a reflexão sobre as questões educacionais. In: PLACCO, V. S. et al. Psicologia \& Educação: revendo contribuições. São Paulo: Educ, 2002.

MARTINS, D. F; NUNES, M. F. O; NORONHA, A. P. P. Satisfação com a imagem corporal e autoconceito em adolescentes. Psicologia: Teoria e Prática, vol. 2, n. 10, p. 94-105, 2008.

OZELLA, S. Adolescência: uma perspectiva crítica. In: CONTINI, M. L. J. et al. Adolescência e psicologia: concepções, práticas e reflexões críticas. Rio de Janeiro. Conselho Federal de Psicologia, 2002.

PAIVA, M. O. A; LOURENÇO, A. A. Rendimento académico: influência do autoconceito e do ambiente de sala de aula. Psicologia: Teoria e Pesquisa, Porto, vol. 27, n. 4, p. 393-402, 2011.

PAMPLIM, R. C. O. A interface família-escola na inclusão de crianças com necessidades educacionais especiais: uma perspectiva ecológica. São Carlos. 155f. Dissertação (Mestrado). Centro de Educação e Ciências Humanas, Universidade Federal de São Carlos, 2005.

PEIXOTO, F. Qualidade das relações familiares, auto-estima, autoconceito e rendimento acadêmico. Análise Psicológica, Lisboa, vol. 22, n. 1, p. 235-244, 2004.

PEIXOTO, F.; ALMEIDA L. S. A Organização do autoconceito: análise da estrutura hierárquica em adolescentes. Psicologia: Reflexão e Crítica, vol. 23, n. 3, p. 533- 541, 2011.

REGO, T. C. Memórias de escola: Cultura escolar e constituição de singularidades. Petrópolis, RJ: Vozes, 2003.

ROCHA, G. V. M; INBERMAN, Y. K; BREUS, B. Análise da relação entre práticas parentais e o autoconceito de pré-escolares. Revista Brasileira de Terapia Comportamental e Cognitiva, v. 13, n. 1, p. 87-106, 2011.

ROSSINI, S. D. R; SANTOS, A. A. A. Fracasso escolar: um estudo documental de encaminhamentos. In: SISTO, F.F. et al. Dificuldades de aprendizagem no contexto psicopedagógico. Petrópolis, RJ: Vozes, 2002.

Barbarói, Santa Cruz do Sul, n. 58, p.<30-46>,jan/jun 2021 
SANTOS, P. L; GRAMINHA, S. S. V. Estudo comparativo das características do ambiente familiar de crianças com alto e baixo rendimento escolar. Cadernos de Psicologia e Educação (Padéia), v.15, n 31, p. 217-226, 2005.

SERASSUELO, H. Comportamento de autoconceito de crianças em idade escolar: um estudo de influências de variáveis antropométricas e psicossocioculturais. São Paulo. 248f. Tese (Doutorado). Escola de Educação Física e Esporte, Universidade Estadual de Campinas, 2007.

SISTO, F. F. Avaliação de dificuldade de aprendizagem: Uma questão em aberto. In: SISTO, F. F; DOBRÁNSZKY, E. A; MONTEIRO, A. Cotidiano escolar: questões de leitura, matemática e aprendizagem. Petrópolis: Vozes, 2002.

SISTO, F. F.; MARTINELLI, S. C. Estudo preliminar para a construção da escala de autoconceito infanto-juvenil (EAC-IJ). Interação em Psicologia, v. 8, n. 2, p. 180-190, 2004a.

SISTO, F. F; MARTINELLI, S. C. Escala de Autoconceito Infanto Juvenil (EAC-IJ). São Paulo: Editora Vetor, 2004b.

SUEHIRO, A. C. B.; RUEDA, F. J. M.; OLIVEIRA, E. Z.; PACANARO, S. V. Avaliação do autoconceito no contexto escolar: análise das publicações em periódicos brasileiros.

Psicologia: Ciência e Profissão, v. 29, n. 1, p. 18-29, 2009.

TEIXEIRA, M. A. P; BARDAGI, M. P; GOMES, W. B. Refinamento de um instrumento para avaliar Responsividade e Exigência parental percebidas na adolescência. Avaliação Psicológica, vol.3, n. 1, p. 1-12 2004.

TEIXEIRA, M. A. P; OLIVEIRA, A. M; WOTTRICH, S. H. Escala de práticas parentais (EPP): avaliando dimensões de práticas parentais em relação a adolescentes. Psicologia: Reflexão e Crítica, vol. 19, n.3, p. 433-441, 2006.

VIGOTSKI, L. S. A construção do pensamento e da linguagem. São Paulo: Martins Fontes, 2001.

Data de recebimento: $21 / 12 / 2013$

Data de aceite: 07/10/2020

\section{Sobre os autores:}

André Lesina Sacilotto é Psicólogo clínico, graduado pela Universidade Franciscana (UFN). Endereço Eletrônico: andrelesina@ hotmail.com

Josiane Lieberknecht Wathier Abaid é Psicóloga, mestre e doutora em Psicologia pelo PPG em Psicologia da Universidade Federal do Rio Grande do Sul (UFRGS). Docente no Curso de Psicologia da Universidade Franciscana (UFN). Endereço Eletrônico: josianelieb@yahoo.com.br 